\title{
DYNAMICS OF WET OXIDATION OF HIGH-AL-CONTENT III-V MATERIALS
}

\author{
CAROL I. H. ASHBY
}

Sandia National Laboratories, Albuquerque, New Mexico 87185-0603

\begin{abstract}
Oxidation of layers of high-Al-content III-V materials by water vapor has become the enabling process for high-efficiency vertical cavity surface emitting lasers (VCSELs) and has potential applications for reducing substrate current leakage in GaAs-on-insulator (GOI) MESFETs. Because of the established importance of wet oxidation in optoelectronic devices and its potential applications in electronic devices, it has become increasingly important to understand the mechanism of wet oxidation and how it might be expected to affect both the fabrication and subsequent operation of devices that have been made using this technique. The mechanism of wet oxidation and the consequence of this mechanism for heterostructure design and ultimate device operation are discussed here.
\end{abstract}

\section{INTRODUCTION}

The rapid oxidation of $\mathrm{AlGaAs}$ with high aluminum mole fraction ( $>85 \% \mathrm{Al})$ using flowing $\mathrm{H}_{2} \mathrm{O} / \mathrm{N}_{2}$ gas mixtures [1] is an enabling technology for high-efficiency vertical cavity surface emitting lasers (VCSELs). Threshold currents below $10 \mu \mathrm{A}$ and threshold voltages only $50 \mathrm{meV}$ above the emitted photon energy have been obtained [2] Wet-oxide-based VCSELs have even demonstrated greater than 50\% wall-plug efficiency [3]. The wet oxidation process is also being studied for electronic applications such as gallium-arsenide-on-insulator (GOI) metel semiconductor field effect transistors (MESFETs) [4] and metal-insulator-semiconductor field effect transistors (MISFETs) [5]. If such devices are to go beyond laboratory demonstration to widespread commercial availability, it is imperative to understand the many factors that influence the extent of oxidation in a particular device and the influence of wet oxidation on relevant device properties. To first order, oxidation rates are determined by $\mathrm{Al}$ mole fraction. However, additional effects related to layer thickness and the nature of the adjacent layers in a device can dominate over mole-fraction effects. Alteration of adjacent unoxidized layers due to the generation of elemental As during the oxidation process can change important optical and electronic properties of a device. A mechanism for wet oxidation and the consequence of this mechanism for heterostructure design and ultimate device operation are discussed here.

\section{EXPERIMENT}

Prior to lateral wet oxidation of $\mathrm{Al}-\mathrm{III}-\mathrm{V}$ heterostructures, the Al-containing layer is exposed by etching a mesa structure to expose the layer to be oxidized. Wet oxidation is usually performed between 375 and $500^{\circ} \mathrm{C}$ in a tube furnace with a water-saturated nitrogen stream passing over the sample to be oxidized [6]. Oxidation begins at the exposed edges and proceeds inward. Because of the strong temperature dependence of the oxidation, a three-zone furnace is especially desirable for well-controlled oxidation profiles. Water temperature and gas flow can be varied to control the supply of $\mathrm{H}_{2} \mathrm{O}$ reactant to the exposed layer edges. Typically, water temperatures between 75 and $95^{\circ} \mathrm{C}$ are employed. The oxidized length can be determined either optically (for sufficiently deep oxidations) or using scanning electron microscopy (SEM). Lateral 
oxidation results presented here were obtained with $80 \pm 0.5^{\circ} \mathrm{C}$ water and a flow rate of $3.0 \mathrm{slm}$ through a 4"-diam. 3-zone tube furnace.

The Raman spectra presented here employed planar 2- $\mu \mathrm{m}$-thick $\mathrm{Al}_{0.98} \mathrm{Ga}_{0.02} \mathrm{As}$ layers on GaAs that were oxidized from the surface down rather than laterally from an exposed edge [7]. Prior to wet oxidation, a $300-\AA$ GaAs cap was selectively removed using a citric acid/peroxide mix [5:1 of (1g citric monohydrate/ $\left.1 \mathrm{~g} \mathrm{H}_{2} \mathrm{O}\right): 30 \% \mathrm{H}_{2} \mathrm{O}_{2}$ ]. Samples were heated to the reaction temperature $\left(400<\mathrm{T}<455^{\circ} \mathrm{C}\right)$ in dry nitrogen. The nitrogen flow $(0.4 \mathrm{slm}$, 2-in. diam. tube) was then switched to bubble through $80 \pm 1{ }^{\circ} \mathrm{C}$ water. The reaction was terminated by switching to a dry nitrogen flow. Raman spectra were measured in the $\mathrm{x}\left(\mathrm{y}^{\prime}, \mathrm{y}^{\prime}+\mathrm{z}^{\prime}\right) \overline{\mathrm{x}}$ backscattering configuration ( $\mathrm{y}^{\prime}$ and $\mathrm{z}^{\prime}$ parallel to (110) planes) using 514.5-nm light at $<85 \mathrm{~W} / \mathrm{cm}^{2}$.

\section{RESULTS AND DISCUSSION}

To first order, oxidation rates are determined by the $\mathrm{Al}$ mole fraction in the oxidizing layer. (Fig. 1). However, the time dependence of the reaction rate for samples with identical $\mathrm{Al}$ mole fraction has been observed to vary depending on individual processing conditions. Many workers operate in a reaction-rate-limited regime (linear time dependence) to facilitate more precise control of oxidized depth in device structures and others report diffusion-limited behavior (parabolic time dependence). Extrapolations of oxidized depth vs. time curves often fail to pass through the origin, with deviations in both directions having been reported. This complicates mechanistic interpretations. However, sufficient information is available about the temperature and composition dependence of wet oxidation rates to support the following understanding of the important dynamic characteristics that determine the time dependence.

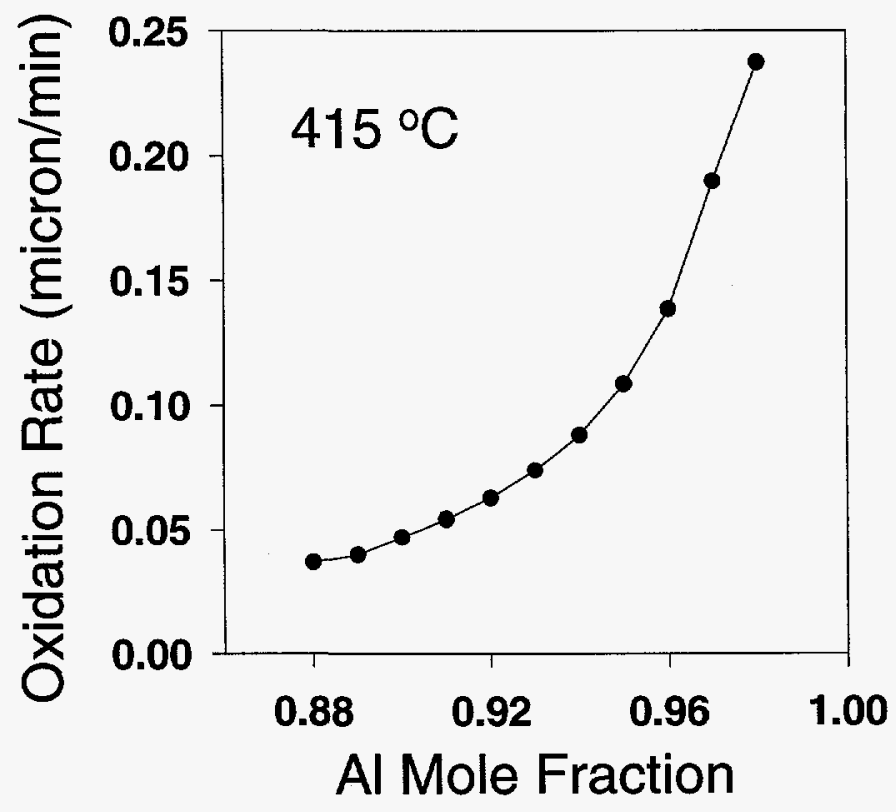

Fig 1. Composition dependence of wet oxidation

The Deal and Grove model for oxidation [8] describes the temporal dependence of an oxidation process as the sum of a linear and a parabolic term, 


\section{DISCLAIMER}

This report was prepared as an account of work sponsored by an agency of the United States Government. Neither the United States Government nor any agency thereof, nor any of their employees, make any warranty, express or implied, or assumes any legal liability or responsibility for the accuracy, completeness, or usefulness of any information, apparatus, product, or process disclosed, or represents that its use would not infringe privately owned rights. Reference herein to any specific commercial product, process, or service by trade name, trademark, manufacturer, or otherwise does not necessarily constitute or imply its endorsement, recommendation, or favoring by the United States Government or any agency thereof. The views and opinions of authors expressed herein do not necessarily state or reflect those of the United States Government or any agency thereof. 


\section{DISCLAIMER}

Portions of this document may be illegible in electronic image products. Images are produced from the best available original document. 


$$
\frac{\mathrm{d}^{2}}{\mathrm{k}_{\mathrm{diff}}}+\frac{\mathrm{d}}{\mathrm{k}_{\mathrm{rxn}}}=\mathrm{t}
$$

where the linear term dominates when the oxidation rate is reaction-rate limited and the parabolic term dominates when the rate is diffusion limited. A range of dependences on time have been reported for wet oxidation of AlGaAs. The oxidation of the most preferred device composition of $\mathrm{Al}_{0.98} \mathrm{Ga}_{0.02} \mathrm{As}$ is generally reported to be linear from 380 to $440^{\circ} \mathrm{C}$ [6], while the oxidation of AlAs has been reported to have a parabolic dependence from 370 to $450{ }^{\circ} \mathrm{C}$ [9]. Another study of AlAs has reported a linear time dependence at $356^{\circ} \mathrm{C}$, a parabolic depencence at $516^{\circ} \mathrm{C}$, and a mixed linear/parabolic dependence at intermediate temperatures [10]. Yet another study of AlAs has shown linear dependence at $\mathrm{T} \leq 350^{\circ} \mathrm{C}$ and parabolic behavior at $\mathrm{T} \geq 375^{\circ} \mathrm{C}$ [11].

To explain why a shift occurs between reaction-rate-limited and diffusion-limited regimes, it is necessary to have an understanding of the chemical nature of the reaction. Raman studies of partially oxidized planar AlGaAs structures always show the presence of a significant amount of elemental As that has been liberated during the oxidation process. Raman spectra of partially oxidized films are dominated by crystalline elemental As peaks at 198 and $257 \mathrm{~cm}^{-1}$ and a broad feature between 200 and $250 \mathrm{~cm}^{-1}$ peaking near $227 \mathrm{~cm}^{-1}$ due to amorphous As [12]. At higher reaction temperatures, significant amounts of $\mathrm{As}_{2} \mathrm{O}_{3}$ are also detected. The broad feature centered at $475 \mathrm{~cm}^{-1}$ is due to amorphous $\mathrm{As}_{2} \mathrm{O}_{3}$ [13]. This species, if present, is below the Raman detection level for oxidations performed at 400 and $425^{\circ} \mathrm{C}$, but it is observed at relatively constant levels throughout the oxidation at $450^{\circ} \mathrm{C}$ (Fig 2). As the oxidation front advances into $\mathrm{AlAs}$ or $\mathrm{AlGaAs}$ films, one observes a relatively constant Raman signal from As and a- $\mathrm{As}_{2} \mathrm{O}_{3}$ while the intensity of the AlAs-like phonon steadily decreases as the AlGaAs is converted to oxide [14].

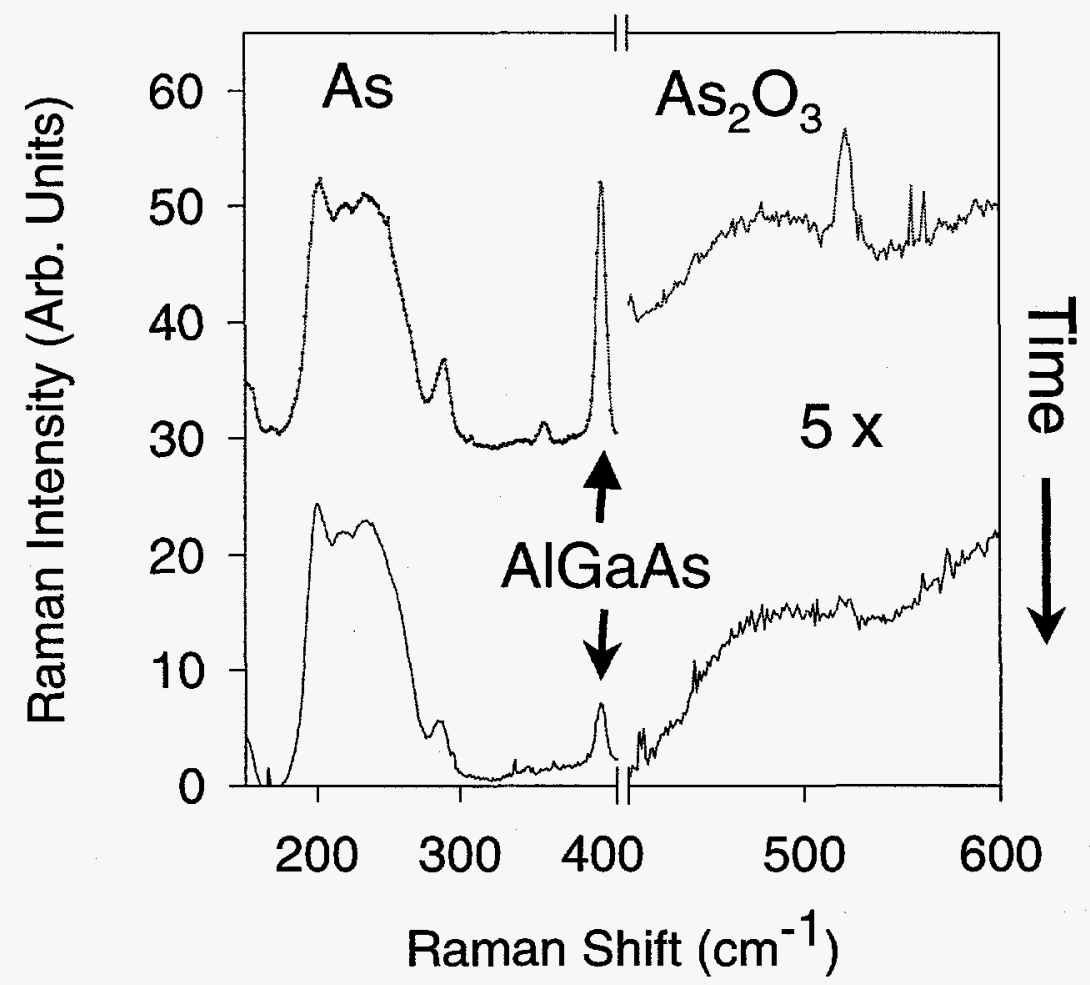

Fig. 2. Time evolution of Raman spectra of $2 \mu \mathrm{m}$ layer of $\mathrm{Al}_{0.98} \mathrm{Ga}_{0.02} \mathrm{As}$ oxidizing at $450{ }^{\circ} \mathrm{C}$. 
Due to the strong ability of low-oxidation state $\mathrm{Al}$ to donate electrons to other atoms, $\mathrm{H}^{+}$ from water can serve as the oxidizing agent for the reaction. In the process, $\mathrm{H}^{+}$becomes zerovalent $\mathrm{H}^{0}$ and can serve as a reducing agent for another species. Both $\mathrm{As}_{2} \mathrm{O}_{3}$ and As are present as intermediates in the wet oxidation process. Their presence can be explained as follows.

Water has been shown to adsorb dissociatively on AlAs at $100 \mathrm{~K}$ under UHV conditions to produce Al-O, Al-OH, and As-H type species on the AlAs surface [15] Since literature values for the thermodynamic quantities of these surface species are unavailable, we have chosen to employ the molecular analogs [16], leading to Eqns. 1 and 2 at a reaction temperature of $425^{\circ} \mathrm{C}$.

$$
\begin{array}{lrl}
2 \mathrm{AlAs}+6 \mathrm{H}_{2} \mathrm{O}_{(\mathrm{g})}=\mathrm{Al}_{2} \mathrm{O}_{3}+\mathrm{As}_{2} \mathrm{O}_{3(\mathrm{l})}+6 \mathrm{H}_{2} & \Delta \mathrm{G}^{698}=-473 \mathrm{~kJ} / \mathrm{mol} \\
2 \mathrm{AlAs}+6 \mathrm{H}_{2} \mathrm{O}_{(\mathrm{g})}=\mathrm{Al}_{2} \mathrm{O}_{3}+2 \mathrm{AsH}_{3} & \Delta \mathrm{G}^{698}=-451 \mathrm{~kJ} / \mathrm{mol}
\end{array}
$$

Under these typical wet oxidation conditions, one would expect both reactions to proceed readily. At $425^{\circ} \mathrm{C}$, further reaction of $\mathrm{As}-\mathrm{H}$ can decompose to give $\mathrm{As}$ and $\mathrm{H}_{2}$, as suggested by the Raman spectra (Eqn 3). It can also react with water to produce $\mathrm{As}_{2} \mathrm{O}_{3}$, but the free energy change is quite small (Eqn. 4). Given the low-temperature UHV results, it is likely that the $\mathrm{As}_{2} \mathrm{O}_{3}$ observed results from the combination of reactions like Eqn 2 and 4. Both $\mathrm{AsH}_{3}$ and $\mathrm{As}_{2} \mathrm{O}_{3}$ can be readily converted to elemental As (Eqns. 3 and 5).

$$
\begin{array}{lrl}
2 \mathrm{AsH}_{3}=2 \mathrm{As}+3 \mathrm{H}_{2} & \Delta \mathrm{G}^{698}=-253 \mathrm{~kJ} / \mathrm{mol} \\
2 \mathrm{AsH}_{3}+3 \mathrm{H}_{2} \mathrm{O}=\mathrm{As}_{2} \mathrm{O}_{3}+6 \mathrm{H}_{2} & \Delta \mathrm{G}^{698}=-22 \mathrm{~kJ} / \mathrm{mol} \\
\mathrm{As}_{2} \mathrm{O}_{3(\mathrm{l})}+3 \mathrm{H}_{2}=2 \mathrm{As}+3 \mathrm{H}_{2} \mathrm{O}_{(\mathrm{g})} & \Delta \mathrm{G}^{698}=-131 \mathrm{~kJ} / \mathrm{mol}
\end{array}
$$

The transition from reaction-limited (linear) to diffusion-limited (parabolic) behavior for a particular AlGaAs composition will depend on the relative temperature dependences of Eqn. 1-5 as $\mathrm{Ga}$ is substituted for Al. Experimental results to date suggest that Eqn. 1 becomes increasingly important for higher $\mathrm{Al}$ contents and higher reaction temperatures.

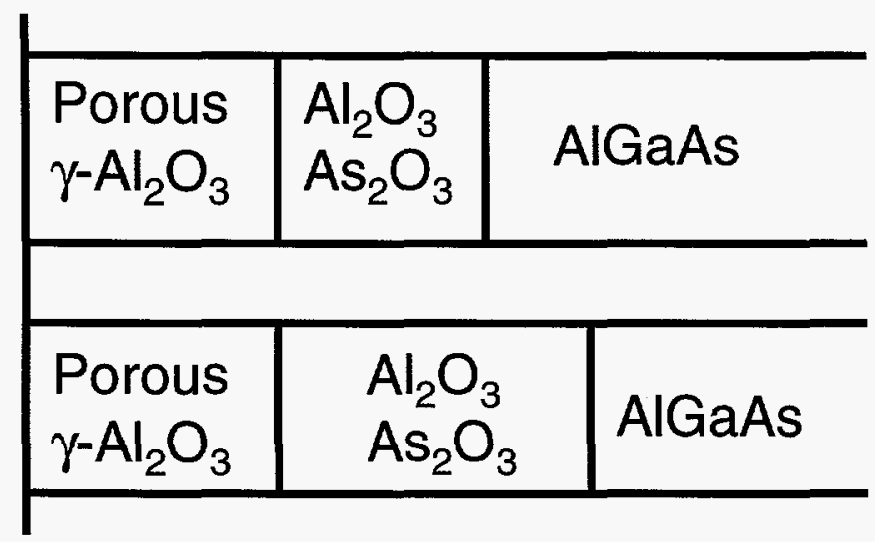

$$
\begin{aligned}
& \mathrm{As}_{2} \mathrm{O}_{3} \text { formation } \\
& \text { and conversion } \\
& \text { to As balanced. }
\end{aligned}
$$

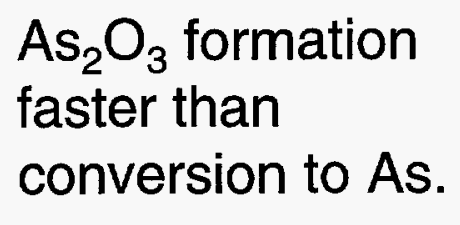

Fig. 3. Schematic of effect of increase in rate of $\mathrm{As}_{2} \mathrm{O}_{3}$ formation relative to its reduction to As for removal to leave behind a porous $\mathrm{As}_{2} \mathrm{O}_{3}$ film. 
The relationship between the rate of formation and conversion of $\mathrm{As}_{2} \mathrm{O}_{3}$ to As (Eqn.1,4, and 5) and the rate of loss of As from the oxidized layer to leave behind a relatively As-free, porous $\mathrm{AlO}_{\mathrm{x}}$ matrix will determine the time dependence of the oxidation rate (Fig. 3). The existence of a thin, dense, amorphous region of a few nanometers thickness has been observed at the oxidation front by transmission electron microscopy (TEM) [17]. Behind this dense region is a less dense region of amorphous $(\mathrm{Al}, \mathrm{Ga})_{2} \mathrm{O}_{3}$ that extends back to the exposed mesa edge. The time-evolution of the thickness of the dense region will determine whether linear or parabolic behavior dominates. When the removal of As is sufficiently fast to balance the rate of formation of $\mathrm{As}_{2} \mathrm{O}_{3}$, a relatively constant thickness of dense oxide consisting of $\mathrm{Al}_{2} \mathrm{O}_{3}$ and $\mathrm{As}_{2} \mathrm{O}_{3}$ will be found near the oxidation fronts it moves deeper into the layer; this will produce the relatively constant $\mathrm{As}_{2} \mathrm{O}_{3}$ Raman intensity observed in films that were partially oxidized at $450{ }^{\circ} \mathrm{C}$. Under these conditions, a linear time dependence will appear because the diffusional contribution to the reaction rate does not increase significantly as the front moves deeper into the layer for typical reaction times. For long reaction times, the deviation from linearity will become increasingly apparent. If reaction conditions are changed to preferentially increase the formation of $\mathrm{As}_{2} \mathrm{O}_{3}$ relative to As loss, a steadily increasing thickness of the dense, $\mathrm{As}_{2} \mathrm{O}_{3}$-containing layer will form and the diffusion-limited parabolic time dependence will become dominant.

The transition from linear to parabolic behavior should be favored by conditions that increase the rate of Eqn. 1 relative to that of Eqn. 5. The greater amounts of $\mathrm{As}_{2} \mathrm{O}_{3}$ seen in the Raman spectra for oxidation at $450^{\circ} \mathrm{C}$ vs. $425^{\circ} \mathrm{C}$ and the relatively constant As signal under the two conditions (Fig. 4) suggest that higher temperatures preferentially enhance Eqn. 1 vs. Eqn. 5 for $\mathrm{Al}_{0.98} \mathrm{Ga}_{0.02}$ As. The transition from predominantly linear to predominantly parabolic with increasing temperature has been previously been reported for AlAs [9-11].

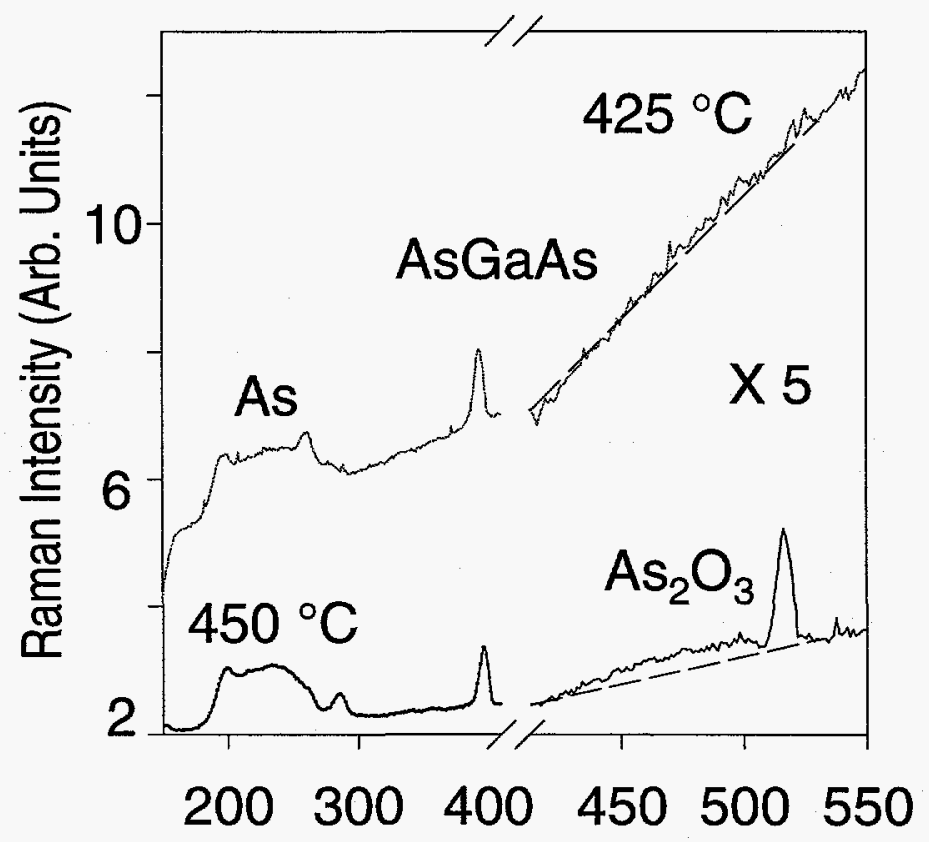

Figure 4. Temperature dependence of Raman spectra a $2 \mu \mathrm{m}$ layer of $\mathrm{Al}_{0.98} \mathrm{Ga}_{0.02} \mathrm{As}$. 
Replacing $\mathrm{Al}$ with $\mathrm{Ga}$ in $\mathrm{Al}_{\mathrm{x}} \mathrm{Ga}_{1-\mathrm{x}} \mathrm{As}$ will affect the favorability of Eqn. 1 and 2, since $\Delta G^{698}$ for Eqns. 1 and 2 for GaAs are respectively $+10 \mathrm{~kJ} / \mathrm{mol}$ and $+32 \mathrm{~kJ} / \mathrm{mol}$, and may thereby retard wet oxidation as $\mathrm{Ga}$ content increases. In contrast, Eqns. 3-5 do not explicitly include either $\mathrm{Al}$ or Ga. Consequently, the reduction of $\mathrm{As}_{2} \mathrm{O}_{3}$ to As should be relatively independent of the $\mathrm{Al} / \mathrm{Ga}$ ratio. One would, therefore, expect that there might be a change in the time dependence of the total wet oxidation reaction when the rates for Eqn. 1-2 are increased or decreased faster than the rates for Eqn. 3-5. For example, the slower rate of Eqn. 1 for higher Ga-content $\mathrm{AlGaAs}$ could produce linear behavior under some conditions that produce parabolic behavior for higher Al-content material. This has, in fact, been observed during oxidation of a structure containing 45 -nm layers of both $98 \%$ and $94 \%$ AlGaAs oxidized at $440^{\circ} \mathrm{C}$ (Fig. 5). In contrast, the slower rates of formation of $\mathrm{As}_{2} \mathrm{O}_{3}$ from both compositions at $400^{\circ} \mathrm{C}$ permits the reduction and loss of As to keep pace with the oxidation process, and linear behavior is observed for both compositions. The transition from reaction-limited to diffusion limited for these samples lies between 0.2 and $1.3 \mu \mathrm{m} / \mathrm{min}$ oxidation rates for the $\mathrm{H}_{2} \mathrm{O}$ temperature and flow rate employed ( $3.0 \mathrm{slm}$ in a 4 "-diam. furnace, $80 \pm 0.5^{\circ} \mathrm{C} \mathrm{H}_{2} \mathrm{O}$ ).
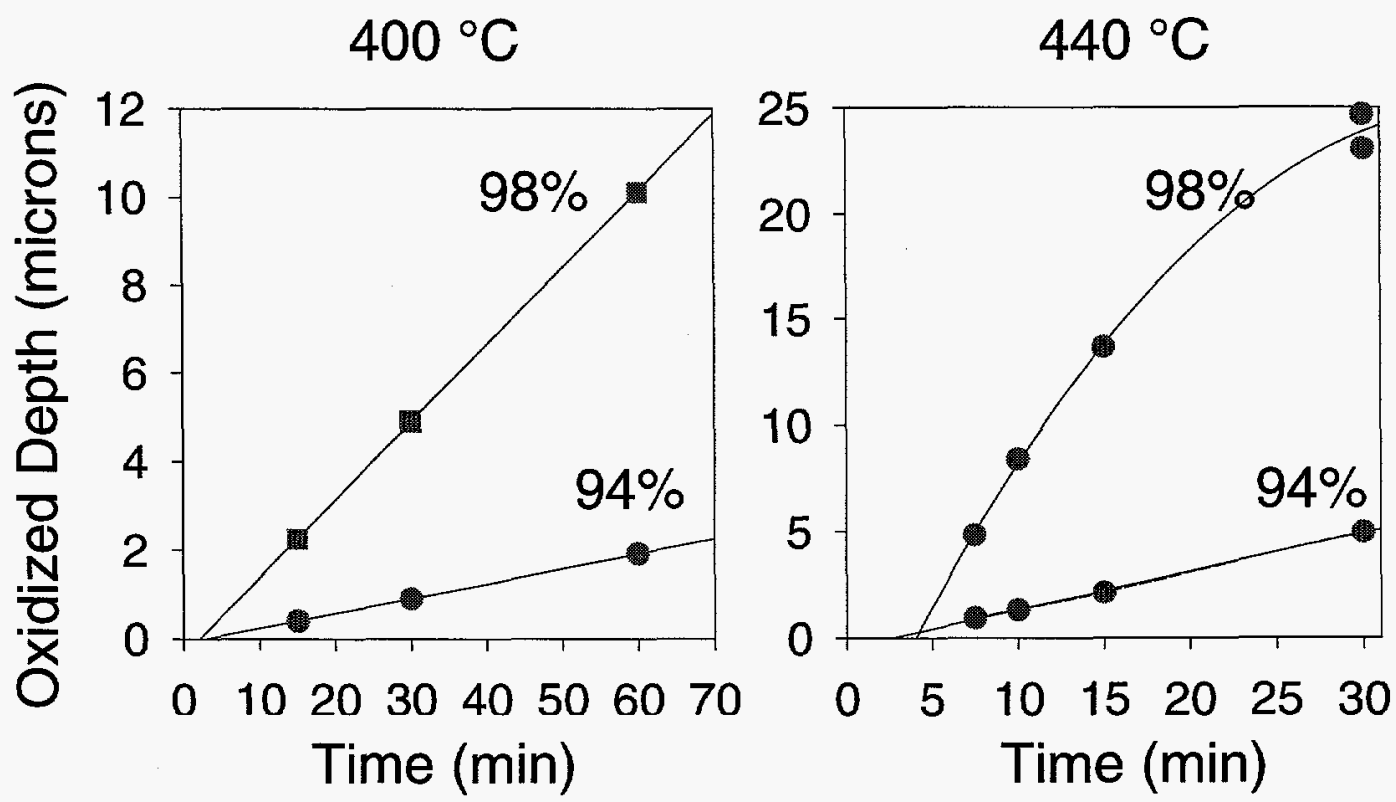

Fig. 5. Temperature dependece of the oxidation of 450- $\AA$ layers of $\mathrm{Al}_{0.09} \mathrm{Ga}_{0.02} \mathrm{As}$ and $\mathrm{Al}_{0.94} \mathrm{Ga}_{0.06} \mathrm{As}$ within the same sample.

Two additional device design characteristics can have a profound effect on the oxidation rate of a specific layer of $\mathrm{AlGaAs}$ as its $\mathrm{Al}$ mole fraction. These are the thickness of the layer to be oxidized and the close proximity of a more rapidly oxidizing layer. Under some conditions, both can prove more important than $\mathrm{Al}$ mole fraction in detemining the relative oxidation rates of different layers in the same structure.

The dependence of oxidation rate on layer thickness is illustrated in Fig. 6 for $\mathrm{Al}_{0.98} \mathrm{Ga}_{0.02} \mathrm{As}$ and $\mathrm{Al}_{0.94} \mathrm{Ga}_{0.06}$ As oxidized at $425^{\circ} \mathrm{C}$ under conditions that yield a linear time dependence for thick layers. For layers thicker than $75 \mathrm{~nm}$, there is very little dependence on layer thickness. In contrast, there is a rapid drop-off of the oxidation rate as the layer thickness decreases below $75 \mathrm{~nm}$. The decrease in oxidation rate as the layers become thinner is sufficient to invert the relative oxidation rates for higher and lower Al-mole-fraction materials when a relatively thick layer of lower $\mathrm{Al}$ content is compared to a thin layer of higher $\mathrm{Al}$ content. The 
mechanism of this decrease in rate has not been definitely identified. It has been suggested that the decrease in very narrow channels is related to the vapor transport coefficient at the gas-oxide interface [18]. An alternative modal has been proposed based on the surface energy of the curvature observed at the oxide tip [19]. The latter model assumes identical contact angles at the top and bottom interfaces; however, a pronounced asymmetry is generally observed, with the contact angle generally being greater at the top interface [17]. In addition, the activation energies so derived are unusually large compared to other literature values. Hence, the gas transport model, though not quantitatively evaluated, appears preferable at this time.

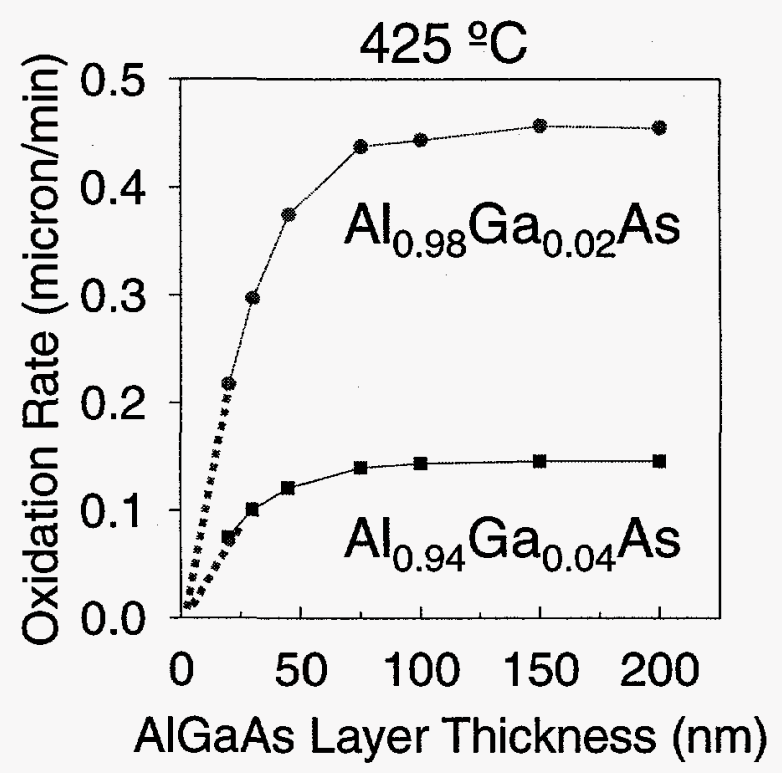

Fig. 6. Thickness dependence of the wet oxidation rate of AlGaAs.

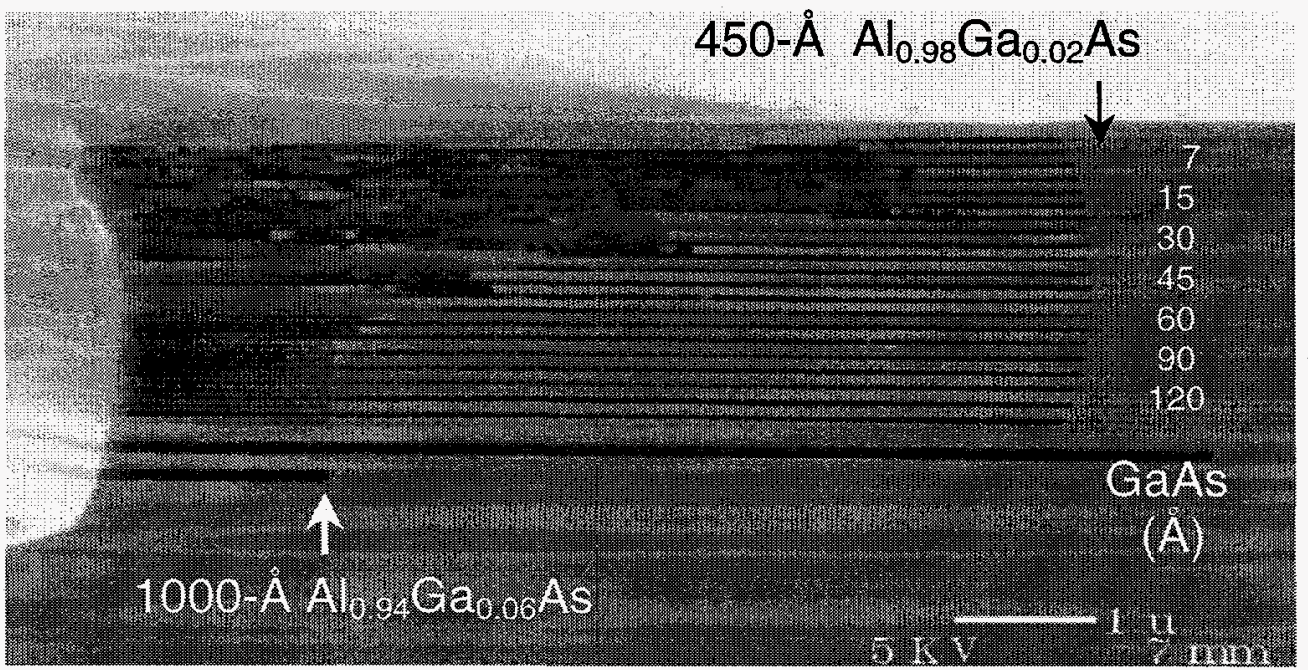

Fig 7. Cross sectional SEM of a partially oxidized $\left(400^{\circ} \mathrm{C}, 90 \mathrm{~min}\right)$ sample of alternating 450 $\AA$ layers of $\mathrm{Al}_{0.98} \mathrm{Ga}_{0.02} \mathrm{As}$ and $\mathrm{Al}_{0.94} \mathrm{Ga}_{0.06} \mathrm{As}$ seperated by $\mathrm{GaAs}$ barriers with thicknesses 
varying from $120 \AA$ near the substrate to $7 \AA$ near the surface. Dark regions are oxide, light regions are unoxidized.

The oxidation rate of a lower-Al-content layer can be appreciably increased when it is in close proximity to a faster-oxidizing layer. The effect of such close-proximity faster-oxidizing layers [14] is shown in Fig. 7 for 45 -nm layers of undoped $\mathrm{Al}_{0.94} \mathrm{Ga}_{0.06} \mathrm{As}$ separated from $45-\mathrm{nm}$ layers of undoped $\mathrm{Al}_{0.98} \mathrm{Ga}_{0.02} \mathrm{As}$ by thin layers of undoped $\mathrm{GaAs}(0.7,1.5,3,6,9$, and $12 \mathrm{~nm})$ oxidized at $400{ }^{\circ} \mathrm{C}$ for $90 \mathrm{~min}$. Although no enhancement of the reaction of the $\mathrm{Al}_{0.94} \mathrm{Ga}_{0.4} \mathrm{As}$ layer is observed after this reaction time with 9 and $12 \mathrm{~nm}$ barriers, there are progressively greater enhancements of the oxidation of the $\mathrm{Al}_{0.94} \mathrm{Ga}_{0.06} \mathrm{As}$ layers that are separated for the already oxidized $\mathrm{Al}_{0.98} \mathrm{Ga}_{0.02}$ As by $6,3,1.5$, and $0.7 \mathrm{~nm}$ GaAs layers. $\mathrm{All} \mathrm{Al}_{0.94} \mathrm{Ga}_{0.06}$ As layers exhibit rate enhancements at longer reaction times. The oxidation of the $\mathrm{Al}_{0.94} \mathrm{Ga}_{0.06} \mathrm{As}$ layers can be modeled as the sum of the unenhanced rate plus a contribution derived from the diffusion of something into the layer from the already oxidized adjacent layers [20]. The close-proximity enhancement is not significant only in the presence of barriers. Structures with graded compositions result in profiles that show appreciably deeper oxidation than expected from compositional effects alone [21]. This proximity enhancement is especially important since compositional grading is used to fabricate tapered oxide current aperatures for optimum VCSEL performance $[6,22]$ and to minimize stresses in the oxidized devices.

Because elemental As is a major product in wet oxidation, it is necessary to consider its influence on important device properties. The presence of large amounts of elemental As at the oxide/semiconductor interface will result in the injection of As interstitials, As $s_{i}$, into the adjacent unoxidized semiconductor. It will also lead to the generation of additional types of point defects [23]:

$$
\begin{aligned}
\mathrm{As}^{0} & \leftrightarrow \mathrm{As}_{\mathrm{i}} \\
\mathrm{As} \mathrm{s}^{0} & \leftrightarrow \mathrm{GaAs}+\mathrm{V}_{\mathrm{Ga}} \\
\mathrm{As} \mathrm{s}_{\mathrm{i}}+\mathrm{Ga}_{\mathrm{Ga}} & \leftrightarrow \mathrm{As}_{\mathrm{Ga}}+\mathrm{Ga}_{\mathrm{i}} \\
\mathrm{As} s_{\mathrm{i}}+\mathrm{V}_{\mathrm{Ga}} & \leftrightarrow \mathrm{As}_{\mathrm{Ga}}
\end{aligned}
$$

Reaction of As with the surface GaAs can lead to the generation of $\mathrm{Ga}$ vacancies, $\mathrm{V}_{\mathrm{Ga}}$. Interstitial As can diffuse into the material and generate $\mathrm{Ga}$ interstitials by displacement to form As antisite defects, $\mathrm{As}_{\mathrm{Ga}}$. Antisite $\mathrm{As}_{\mathrm{Ga}}$ can also form by reaction with $\mathrm{Ga}$ vacancies. The increased concentrations of these point defects can be quite deleterious for devices made using wet oxidation.

The most gross evidence for the large quantities of point defects that are produced during wet oxidation is the appearance of As precipitates quite remote from the original oxidation. Such As precipitates have been observed widely dispersed through the adjoining layers and even segregated at the GaAs surface of a wet-oxidized sample [24]. Precipitates have also been reported in the InGaAs channel of a GOI MESFET that had a $10 \mathrm{~nm} \mathrm{Al}_{0.25} \mathrm{Ga}_{0.75} \mathrm{As}$ layer interposed between the channel and the oxidized layer [25 ].

The photoluminescence from quantum wells that are near wet-oxidized regions exhibits changes that are typically seen in the presence of excessive numbers of point defects. The photoluminescence is decreased for quantum wells (QWs) situated 20 and $40 \mathrm{~nm}$ from oxidized 
AlAs [26]. The time and temperature dependence of this degradation is consistent with the presence of oxidation-generated point defects that have diffusivity comparable to As in GaAs. Post-oxidation hydrogen treatment partially restores the photoluminescence intensity from GaAs quantum wells separated from the oxidized layer by 25-nm AlGaAs spacers. [27] While oxidation reduces the PL intensity to $6 \%$ of the original intensity, post-oxidation $\mathrm{H}$-annealing restores the intensity to $67 \%$ of its original level. Such PL restoration is to be expected from hydrogen passivation of As-associated deep levels, e.g., $\mathrm{As}_{\mathrm{Ga}}$, that were formed during oxidation by indiffusion of excess As.

Intermixing at quantum well interfaces by heating is seen to be greater near oxidized AlGaAs regions than near unoxidized regions of the same device. However, even the QW emission from the regions that are not immediately above or below oxidized material exhibit a blue-shift. Such behavior is expected if there is increased mobility of column III atoms in the presence of excess As [28]

In addition to the observation of As precipitates in the InGaAs channel of a GOI MESFET, a deterioration of both the mobility and the free carrier concentration is obtained following oxidation. This deterioration was minimized by decreasing oxidation temperature and/or oxidation time [25]. Both process alterations would reduce the diffusion of As-derived defects into the device, thereby minimizing device degradation.

\section{SUMMARY}

Wet oxidation of high-Al-content $\mathrm{AlGaAs}$ produces both elemental $\mathrm{As}$ and $\mathrm{As}_{2} \mathrm{O}_{3}$ as important products that can remain near the reaction front. The thickness of the $\mathrm{As}_{2} \mathrm{O}_{3}$-containing region at the oxide/semiconductor interface will determine the time-dependence of the process. A shift from reaction-rate-limited (linear) to diffusion-limited (parabolic) time dependence is favored by increasing temperature or increasing $\mathrm{Al}$ mole fraction. The elemental As that is produced in the reaction acts as a source of defects that can affect important chemical and electrical properties of devices. Free As is an inherent part of the wet oxidation process that cannot be totally avoided so applications of these oxides must either not depend strongly on concentrations of point defects in the material or attempts must be made to design around the endemic As problem.

\section{ACKNOWLEDGMENTS}

The author wishes to acknowledge her Sandia colleagues working in the oxidation area: Andrew A. Allerman, Albert G. Baca, Olga Blum, Monica M. Bridges, Kent D. Choquette, David M. Follstaedt,,Kent M. Geib, Michael J. Hafich, B.E. Hammons, Hong Q. Hou, Nancy A. Missert, Paula P. Newcomer, John P. Sullivan, and Ray D. Twesten. Sandia is a multiprogram laboratory operated by Sandia Corporation, a Lockheed Martin Company, for the United States Department of Energy under Contract DE-AC04-94AL85000.

\section{REFERENCES}

1. J. M. Dallesasse, N. Holonyak, Jr., A. R. Sugg, T. A. Richard, and N. El-Zein, Appl. Phys. Lett. 57,2844 (1990).

2. K. D. Choquette, R.P. Schneider, Jr., K. L. Lear, and K. M. Geib, Electroni. Lett. 30, 2043 (1994). 
3. K.L. Lear, J.D. Choquette, R.P. Schneider, Jr., S.P. Kilcoyne, and K. M. Geib, Electron. Lett. 31, 208 (1995).

4. P.A. Parikh, P. M. Chavarkar, and U.K. Mishra, IEEE Electron. Device Lett. 18, 111 (1997).

5. E.I.Chen, N.Holonyak, Jr., and S.A Maranowski, Appl. Phys. Lett. 66, 2688, (1995).

6. K. D. Choquette, K. M. Geib, C. I. H. Ashby, R. D. Twesten, O. Blum, H. Q. Hou, D. M.

Follstaedt, B. E. Hammons, D. Mathes, and R. Hull, IEEE J. Select. Topics in Quant. Electron. 3, 916 (1997).

7. C. I. H. Ashby, J. P. Sullivan, P.P. Newcomer, N. A. Missert, H. Q. Hou. B. E. Hammons, M.

J. Hafich, and A. G. Baca, Appl. Phys. Lett. 70, 2443 (1997).

8. B. E. Deal and A. S. Grove, J. Appl. Phys. 36, 3770 (1965).

9. T. Langenfelder, St. Schröder, and H. Grothe, J. Appl.Phys. 82, 3548 (1997).

10. M. Ochiai, G. E. Giudice, H. Temkin, J. W. Scott, and T. M. Cockerill, Appl. Phys. Lett. 68, 1898 (1996).

11. S. A. Feld, J. P. Loehr, R. E. Sherriff, J. Miemeri, and R. Kaspi, IEEE Photon. Technol. Lett. 10, 197 (1998).

12. G.P. Schwartz, B. Schwartz, D. DiStefano, G.J. Gualtieri, and J.E. Griffiths, Appl. Phys.

Lett. 34, 205 (1979).

13. G.P. Schwartz, G.J. Gualtieri, J.E. Griffiths, C.D. Thurmond, B. Schwartz, J. Electrochem.

Soc. 127, 2488 (1980).

14. C. I. H. Ashby, J. P. Sullivan, K. D. Choquette, K.M. Geib, and H. Q. Hou, J. Appl. Phys. 82, 3134 (1997).

15. W. J. Mitchell, C.-H. Chung, S.I. Yi, E.L. Hu, and W.H. Weinberg, J. Vac. Sci. Technol.

B15, 1182 (1997).

16. Thermochemical data used in calculations found in O. Kubaschewski, C. B. Alcock, P. J.

Spencer, "Materials Thermochemistry", Pergamon Press, UK, 1993.

17. R. D. Twesten, D. M. Follstaedt, and K. D. Choquette, "Vercital-Cavity Surface Emitting

Lasers, K. D. Choquette and D. G. Deppe, eds., Proc. SPIE-The International Society for

Optical Engineering Proceedings 3003, 55 (1997).

18. J.-H. Kim, D. H. Lim, K. S. Kim, G M. Yang, K. Y Lim, and H. J. Lee, Appl. Phys. Lett. 69, 3357 (1996).

19. R. L. Naone and L. A. Coldren, J. Appl. Phys. 82, 2277 (1997).

20. O. Blum, C. I. H. Ashby, and H. Q. Hou, Appl. Phys. Lett. 70, 2870 (1997).

21. O. Blum, K. L. Lear, H. Q. Hou, and M. E. Warren, Electron. Lett. 32, 1406 (1996).

22. R. L. Naone, E. R. Hegbloom, B. J. Thibeault, and L. A. Coldren, Electron. Lett. 33, 300 (1997).

23. T. Y. Tan, Mater. Sci. and Engin. B10, 227 (1991).

24. Z. Liliental-Weber, S. Ruvimov, W. Swider, J. Washburn, M. Li, G.S. Li,

and C. Chang-Hasnain, and E.R. Weber et al., SPIE--The International Society for

Optical Engineering Proceedings 3006, 15 (1997).

25. P.A. Parikh, P.M. Chavarkar, L. Zhao, J. Ibbetson, J.S. Speck, U.K. Mishra,

"Effect of oxidation of AlxGa1-xAs on Adjacent Semiconductor Layers : Hall (Electrical) and

TEM (Structural Characterization)", 1997 EMC Proceedings, pp 40.

26. S. S. Shi, Ph.D. thesis, 'Hydrogen Passivation of Native Oxides in GaAs-based III-V

Devices', September 1997.

27. S. S. Shi, E. L. Hu, J.-P. Zhang, Y.-I. Chang, P. Parikh, and U. K. Mishra, Appl. Phys. Lett.

70, 1293 (1997).

28. C.-K. Lin, X. Zhang, P. D. Dapkus, and D. H. Rich, Appl. Phys. Lett. 71, 3108 (1997). 